\title{
The Influence of Wind Power on the Small Signal Stability of a Power System
}

\author{
T.R. Ayodele, A.A. Jimoh, J.L Munda, J.T Agee \\ Department of Electrical Engineering. \\ Tshwane University of Technology \\ Pretoria, South Africa \\ Phone: +27735605380, e-mail: AyodeleTR@tut.ac.za, JimohAA@tut.ac.za, MundaJL@tut.ac.za, AgeeJT@tut.ac.za
}

\begin{abstract}
This paper analyses the influence of wind power on the small signal stability of a power system. Factors like power dispatch, generator technology, wind farm location and wind power integration level are considered. The oscillatory modes that arise as a result of changes in system operating conditions are computed using modal analysis. Participation factors are also calculated to determine the relative contribution of each system state variables to a certain mode. Time domain simulations are carried out to validate the conclusion inferred from the modal analysis.
\end{abstract}

\section{Key words}

Wind power, small signal stability, modal analysis, damping ratio, Power system.

\section{Introduction}

Grid integration of wind power today has achieved a considerable development. This fact is leading to a growing concern about its influence on the operation of a power system [1]. Much of these concerns are centred on the impact of wind power integration on the transient and voltage stability with less attention given to the small signal stability.

Small signal stability is considered when there are small changes in operating parameters of a power system [2]. These changes can result in electromechanical oscillation but mostly decay with time and thus the system comes back to stable operating point. However, if the system is not adequately damped, the oscillation can lead to loss of synchronism.

Small signal stability studies are based on linearised system around the operating point. The differential equations that describe the dynamic system are linearised and the system eigenvalues are computed from the characteristic equation. Majorly, there are two kinds of oscillation usually considered in small signal stability studies, the local area oscillations and the inter-area oscillations. Participation of each generator's state variables to a particular mode of interest is computed from the participation matrix. The information obtained here is used to identify the critical generators that can cause instability and hence appropriate measures can be taken.

The different methods that have been used in the literatures for analysing small signal stability of a large power system include prony analysis, Fourier-method [3], modal analysis method, time domain analysis and Probabilistic method $[4,5]$. The issue of constant speed wind turbine generator on power system oscillation was studied in [3], impact of large scale wind power was analysed in [1] using three area network and modal analysis of doubly-fed induction generator was presented in [6] where the main focus is on the control mode.

The objective of this paper is to identify the influence of wind power on the power system small signal stability considering factors like direction of power flow in the tie-line, Transmission line length of the location of wind resources to the main grid, integration level and generator technology.

The paper is organised as follows: section two presents the model of wind generators, the methodology of the study is described in section three, the test system and simulation results in different scenario are given in section four while the conclusion is presented in section five.

\section{Characteristic and Modelling of Wind Generators}

The per unit d-q stator, rotor voltage equation and the flux linkage equation of an induction machine in a synchronously rotating reference frame are given in equations(1)-(4) [7]. The generator convention is adopted i.e the stator and rotor currents are positive when flowing towards the network and both active and reactive power are also positive when flowing towards the grid.

$$
\begin{aligned}
& \mathrm{V}_{\mathrm{qs}}=-\mathrm{r}_{\mathrm{s}} \mathrm{i}_{\mathrm{qs}}-\psi_{\mathrm{ds}}-\frac{1}{\omega_{\mathrm{s}}} \mathrm{p} \psi_{\mathrm{qs}} \\
& \mathrm{V}_{\mathrm{ds}}=-\mathrm{r}_{\mathrm{s}} \mathrm{i}_{\mathrm{ds}}+\psi_{\mathrm{qs}}-\frac{1}{\omega_{\mathrm{s}}} \mathrm{p} \psi_{\mathrm{ds}} \\
& \mathrm{V}_{\mathrm{qr}}=-\mathrm{r}_{\mathrm{r}} \mathrm{i}_{\mathrm{qr}}-\mathrm{s} \psi_{\mathrm{dr}}-\frac{1}{\omega_{\mathrm{s}}} \mathrm{p} \psi_{\mathrm{qr}} \\
& \mathrm{V}_{\mathrm{dr}}=-\mathrm{r}_{\mathrm{r}} \mathrm{i}_{\mathrm{dr}}+\mathrm{s} \psi_{\mathrm{qr}}-\frac{1}{\omega_{\mathrm{s}}} \mathrm{p} \psi_{\mathrm{dr}}
\end{aligned}
$$


The flux linkage equations are written as

$$
\begin{aligned}
& \psi_{\mathrm{qs}}=\mathrm{X}_{\mathrm{s}} \mathrm{i}_{\mathrm{qs}}+\mathrm{X}_{\mathrm{m}} \mathrm{i}_{\mathrm{qr}} \\
& \psi_{\mathrm{ds}}=\mathrm{X}_{\mathrm{s}} \mathrm{i}_{\mathrm{ds}}+\mathrm{X}_{\mathrm{m}} \mathrm{i}_{\mathrm{dr}} \\
& \psi_{\mathrm{qr}}=\mathrm{X}_{\mathrm{r}} \mathrm{i}_{\mathrm{qr}}+\mathrm{X}_{\mathrm{m}} \mathrm{i}_{\mathrm{qs}} \\
& \psi_{\mathrm{dr}}=\mathrm{X}_{\mathrm{r}} \mathrm{i}_{\mathrm{dr}}+\mathrm{X}_{\mathrm{m}} \mathrm{i}_{\mathrm{ds}}
\end{aligned}
$$

where,

$$
\mathrm{X}_{\mathrm{s}}=\mathrm{X}_{\mathrm{Ls}}+\mathrm{X}_{\mathrm{m}} \text { and } \mathrm{X}_{\mathrm{r}}=\mathrm{X}_{\mathrm{Lr}}+\mathrm{X}_{\mathrm{m}}
$$

The subscripts, s, and, $r$, denote the stator and the rotor quantities respectively, $r$, is the resistance, $i$, is the current, $\psi$ is the flux linkage per second, $\mathrm{X}$, is the reactance, $S$ is the slip, $\omega s$ is the synchronous speed, $p$ is the differential term $(\mathrm{d}(.) / \mathrm{dt}) . \mathrm{X}_{\mathrm{m}}, \mathrm{X}_{\mathrm{Ls}}$ and $\mathrm{X}_{\mathrm{Lr}}$ are the magnetizing, stator leakage and rotor leakage reactances respectively. All the rotor quantities are referred to the stator. For squirrel cage induction generator $\mathrm{V}_{\mathrm{qr}}=\mathrm{V}_{\mathrm{dr}}=0$, because the rotor is short-circuited. The electromagnetic torque developed by the generator is written as

$$
\mathrm{T}_{\mathrm{em}}=\frac{1}{\omega_{\mathrm{s}}} \mathrm{X}_{\mathrm{m}}\left(\mathrm{i}_{\mathrm{qs}} \mathrm{i}_{\mathrm{idr}}-\mathrm{i}_{\mathrm{ds}} \mathrm{i}_{\mathrm{qr}}\right)
$$

The mechanical coupling between the generator and the turbine with one mass system assumed is given by.

$$
2 \mathrm{H} \frac{\mathrm{d} \omega \mathrm{r}}{\mathrm{dt}}=\mathrm{T}_{\mathrm{m}}-\mathrm{T}_{\mathrm{em}}
$$

Where $\mathrm{H}$ and $\mathrm{T}_{\mathrm{m}}$ are the per unit turbine inertia and mechanical torque respectively.

\section{A. Wind Generators Model for Stability Studies}

For stability studies, voltage behind a transient impedance model is usually adopted with some simplification [8]. Machine stator transients is neglected i.e $\mathrm{p} \psi_{\mathrm{qs}}=0, \quad \mathrm{p} \psi_{\mathrm{ds}}=0$. In this way, the stator differential voltage equation in (1) and (2) is simplified into an arithmetic equation. This is referred to as third order reduced model in the literature. However, to obtain this model, equations (1)-(8) in section two are rearranged and the following new terms are defined.

$\mathrm{e}_{\mathrm{qs}}=\left(\frac{\mathrm{X}_{\mathrm{m}}}{\mathrm{X}_{\mathrm{r}}}\right) \psi_{\mathrm{dr}}, \mathrm{e}_{\mathrm{ds}}=\left(\frac{\mathrm{X}_{\mathrm{m}}}{\mathrm{X}_{\mathrm{r}}}\right) \psi_{\mathrm{qr}}, \mathrm{X}^{\prime}=\mathrm{X}_{\mathrm{s}}-\frac{\mathrm{X}_{\mathrm{m}}^{2}}{\mathrm{X}_{\mathrm{r}}}, \mathrm{T}_{\mathrm{o}}=\frac{\mathrm{X}_{\mathrm{r}}}{\omega_{\mathrm{s}} \mathrm{r}_{\mathrm{r}}}$

The state space model obtained is given by

$$
\dot{\mathrm{x}}=\mathrm{Ax}+\mathrm{Bu}
$$

where,

$$
\mathrm{x}=\left(\begin{array}{ll}
\mathrm{e}_{\mathrm{qs}} & \mathrm{e}_{\mathrm{ds}}
\end{array}\right)^{\mathrm{T}}, \mathrm{u}=\left(\begin{array}{llll}
\mathrm{V}_{\mathrm{qs}} & \mathrm{V}_{\mathrm{ds}} & \mathrm{V}_{\mathrm{qr}} & \mathrm{V}_{\mathrm{dr}}
\end{array}\right)^{\mathrm{T}}
$$

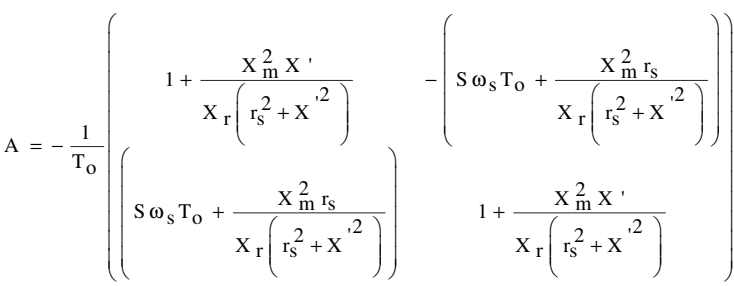

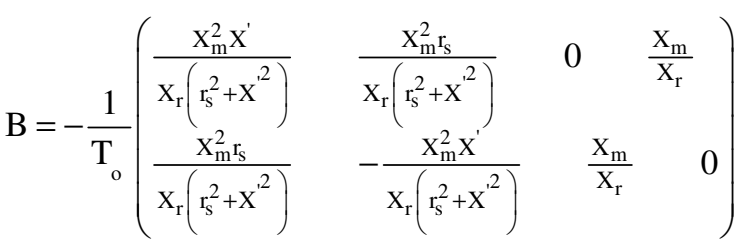

\section{Methodology}

Modal analysis method is adopted in this paper because it proves to be superior compared to other methods, as it provides additional information to identify the critical generators that may be used to determine the location of eventually needed stabilizing devices in order to influence the system damping efficiently. The dynamic behaviour of a large complex non linear system such as a power system can be represented by (12) and (13).

$$
\begin{aligned}
& \dot{\mathrm{x}}=f(\mathrm{x}, \mathrm{u}, \mathrm{t}) \\
& \mathrm{y}=\mathrm{g}(\mathrm{x}, \mathrm{u}, \mathrm{t})
\end{aligned}
$$

where

$$
\begin{aligned}
& \mathrm{x}=\left(\mathrm{x}_{1}, \mathrm{x}_{2}, \ldots ., \mathrm{x}_{\mathrm{n}}\right)^{\mathrm{T}} \\
& \mathrm{u}=\left(\mathrm{u}_{1}, \mathrm{u}_{2}, \ldots, \mathrm{u}_{\mathrm{n}}\right)^{\mathrm{T}}
\end{aligned}
$$

$\mathrm{x}$ is the state vector, $\mathrm{u}$ is the input vector and $\mathrm{y}$ is the output vector.

To study the small signal characteristic behaviour of a dynamic system, its singular point is important; conclusion about stability can be drawn from a linearised system. Therefore the non linear equation (12) and (13) are linearised using Taylor series. The linear result equation is written as (14)and (15) [9].

$$
\begin{aligned}
& \Delta \dot{\mathrm{x}}=\mathrm{A} \Delta \mathrm{x}+\mathrm{B} \Delta \mathrm{u} \\
& \Delta \mathrm{y}=\mathrm{C} \Delta \mathrm{x}+\mathrm{D} \Delta \mathrm{u}
\end{aligned}
$$

Taking the Laplace transformation will result in equations (16) and (17)

$$
\begin{aligned}
& \Delta \dot{\mathrm{x}}(\mathrm{s})=\frac{\operatorname{adj}(\mathrm{sI}-\mathrm{A})}{\operatorname{det}(\mathrm{sI}-\mathrm{A})} \mathrm{B} \Delta \mathrm{u}(\mathrm{s}) \\
& \Delta \mathrm{y}(\mathrm{s})=\mathrm{C} \frac{\operatorname{adj}(\mathrm{sI}-\mathrm{A})}{\operatorname{det}(\mathrm{sI}-\mathrm{A})} \mathrm{B} \Delta \mathrm{u}(\mathrm{s})+\operatorname{Du}(\mathrm{s})
\end{aligned}
$$

The poles of $\Delta x(s)$ and $\Delta y(s)$ are the roots of the characteristic equation (18)

$$
\operatorname{det}(\mathrm{sI}-\mathrm{A})=0
$$

Equation (18) can be re-written as (19)

$$
\operatorname{det}(\lambda I-A)=0
$$


The value of $\lambda$ that satisfies equation (19) are the eigenvalues of matrix A. It contains information about the response of the system to a small perturbation. The eigenvalue can be real and/or complex. The complex values appear in conjugate pairs if A is real (20).

$$
\lambda_{i}=\sigma_{i} \pm j \omega_{i}
$$

Each eigenvalue represents a system mode and the relationship between this mode and the stability is given by Lyapunov's first method [2]

(i) Stable system, then $\sigma_{\mathrm{i}}<0$

(ii) Unstable system, then $\sigma_{i}>0$

(iii) When $\sigma_{i}=0$, then nothing can be said in general

The frequency of oscillation in, $\mathrm{Hz}$, and the damping ratio are given by (21) and (22).

$$
\begin{aligned}
& f=\frac{\omega_{i}}{2 \pi} \\
& \xi=\frac{-\sigma_{i}}{\sqrt{\sigma_{i}^{2}+\omega_{i}^{2}}}
\end{aligned}
$$

The participation factor of mode $\mathrm{i}$, can be computed using (23) and (24) [8]

$$
\begin{aligned}
& \mathrm{p}_{\mathrm{i}}=\left(\begin{array}{c}
\mathrm{p}_{1 \mathrm{i}} \\
\mathrm{p}_{2 \mathrm{i}} \\
\ldots . \\
\mathrm{p}_{\mathrm{mi}}
\end{array}\right) \\
& \mathrm{p}_{\mathrm{ki}}=\frac{\left|\Phi_{\mathrm{ki}}\right|\left|\Psi_{\mathrm{ik}}\right|}{\sum_{\mathrm{k}=1}^{\mathrm{n}}\left|\Phi_{\mathrm{ki}}\right|\left|\Psi_{\mathrm{ik}}\right|}
\end{aligned}
$$

$\mathrm{m}$ is the number of state variables, $\mathrm{p}_{\mathrm{ki}}$ is the participation factor of the $\mathrm{k}^{\text {th }}$ state variable into mode $\mathrm{i}, \Phi_{\mathrm{ki}}$ is the $\mathrm{i}^{\text {th }}$ element of the $\mathrm{k}^{\text {th }}$ right eigen vector of $\mathrm{A}, \Psi_{\mathrm{ik}}$ is the $\mathrm{m}^{\text {th }}$ element of the $\mathrm{i}^{\text {th }}$ left-eigenvector of $\mathrm{A}$.

\section{The System under Study and the Result of the Modal Analysis}

The system under study consists of the popular two area network in reference [2]. The data used is the same with the one given in [2]. The system without wind power integration serves as the base case (BC). For the number of states to be limited in order to reduce the complexity of the problem and to improve usability of result, the synchronous generators are not equipped with exciters. This is considered appropriate according to reference [9] to gather a qualitative insight. It is however necessary to model the exciters when considering a detailed quantitative modelling of real power system [9].

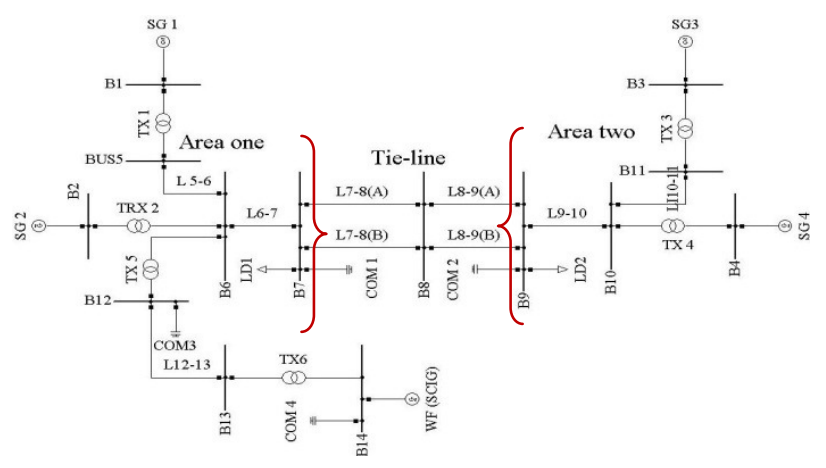

Figure 1: The system under study.

In the system under study, 439.96MW of power is exported from area one to area two. The eigenvalues of the $\mathrm{BC}$ are computed, 24 eigenvalues were obtained with negative real part. According to Lyapunov, this system is small signal stable. Six of the eigenvalues are complex, denoting an oscillatory mode. Only the results of the oscillatory mode are given in table 1 .

Table 1: Electromechanical mode of the study system

\begin{tabular}{|l|l|l|l|}
\hline Mode & $\lambda=\sigma \pm \mathrm{j} \omega$ & $f, \mathrm{~Hz}$ & $\xi$ \\
\hline$*$ & $-1.030 \pm 9.002$ & 1.433 & 0.114 \\
\hline$* *$ & $-0.715 \pm 8.065$ & 1.284 & 0.088 \\
\hline$\Delta$ & $-0.069 \pm 3.427$ & 0.545 & 0.020 \\
\hline
\end{tabular}

* Local mode in area one.

** Local mode in area two.

$\Delta$ Inter area mode between area one and area two.

The modal bar diagram showing the speed participation of the generators of the inter-area mode which has the least damping ratio is presented in figure 2

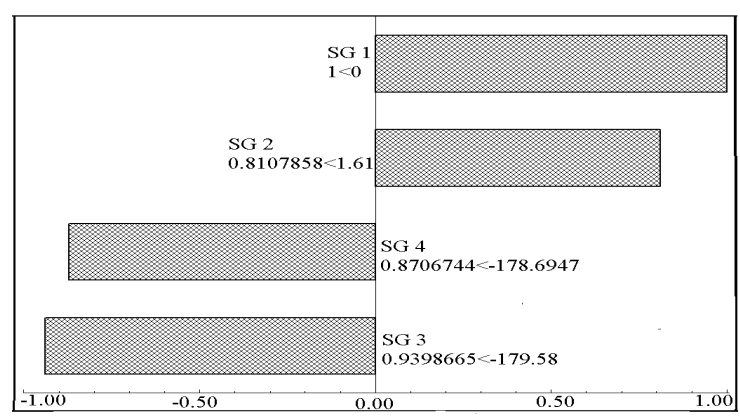

Figure 2: Speed participation bar plot of the inter-area mode

A small disturbance of $1 \mathrm{~ms}$ fault duration was created at time, $\mathrm{t}=0$, at the middle of line $7-8 \mathrm{~A}$, the speed deviation of the generators is presented in figure (3). The plot shows that the generators in area 1 oscillate against the generators in area 2 thereby confirming the result of the modal analysis. 


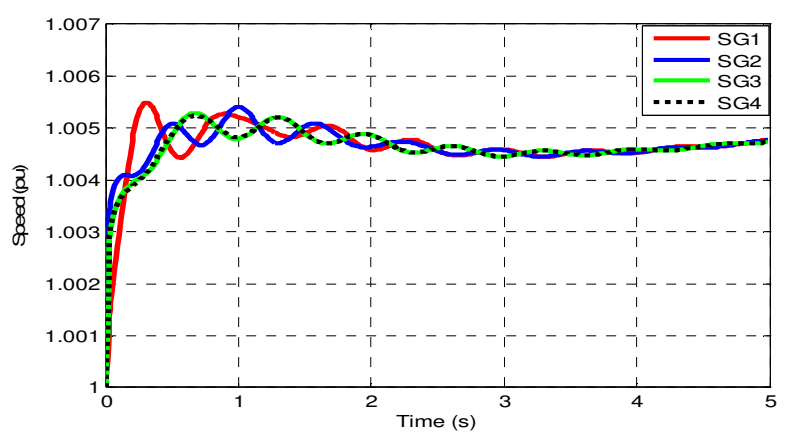

Figure 3: Speed deviation of the 4 machines in the two area network during $1 \mathrm{~ms}$ fault duration at line (7-8A)

\section{A. Wind Farm Integration}

The wind farm (WF) is assumed to consist of $2 \mathrm{MW}$, $0.69 \mathrm{kV}$ generators modelled as an aggregate wind farm in line with [10] to the required MW of power. Aggregate model reduces simulation time required by detailed multi turbine system. It is also assumed that the wind farms are located far from the grid where the wind resources are located as the case for most real wind farms; therefore the WF is connected to the system at B 6 through a $25 \mathrm{~km}$ line and two transformers $(0.69 / 20 \mathrm{kV}, 20 / 230 \mathrm{kV})$. The WF consisting of squirrel cage induction generators (SCIG) is adequately compensated with shunt capacitor at $0.69 \mathrm{kV}$ and $20 \mathrm{kV}$ buses to ensure a satisfactory voltage level at all the buses. The wind farm made up of doubly-fed induction generators (DFIG) is connected to the grid through a three phase transformer and power is injected into the grid at unity power factor. This is achieved through the pulse-with modulation frequency converter between the rotor of the generator and the grid. The detailed model of the converter and its associated controllers can be found in [11].

The scenarios considered are discussed in the various subheadings

\section{1) Influence of Wind Power Penetration on the Oscillatory Modes of a Power System}

A wind farm made up of SCIG was connected to bus 6 . The power from the wind farm was gradually increased by $100 \mathrm{MW}$ while reducing the power output of SG2 by the same amount so that the total power in area one remains the same. The results show that the damping of the low frequency inter-area mode decreases while the local modes are positively influenced. This is presented in figure 4. The technology of the generators making up the wind farm was changed to DFIG and the influence of wind power penetration was again studied. The result is presented in figure 5 .

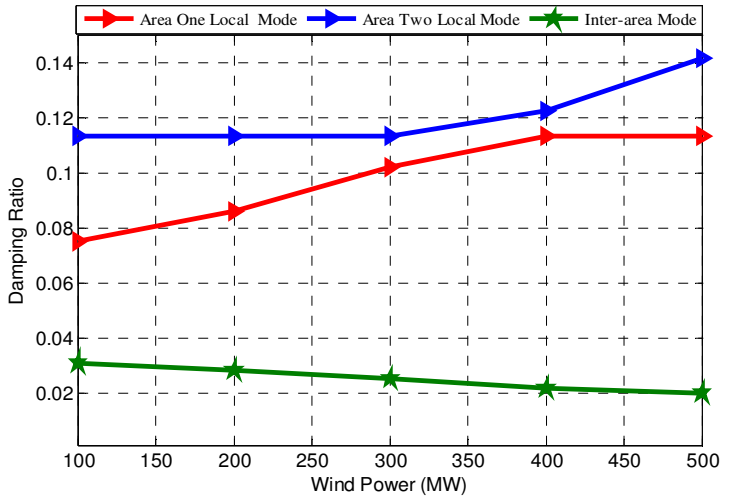

Figure 4: Influence of wind power penetration using SCIG on the damping of electromechanical mode

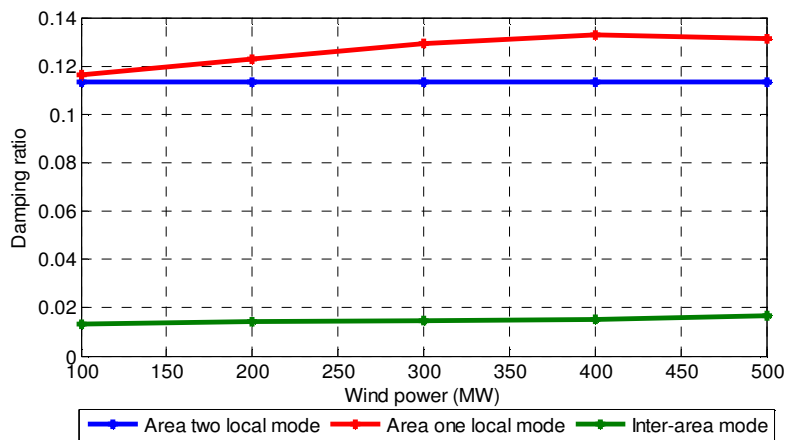

Figure 5: Influence of wind power penetration using DFIG on the damping of electromechanical mode

From the result shown in figure 5, area one local mode is positively influenced by the wind farm. The inter-area mode is slightly positively influenced while the influence on area two local mode is not clear as it shows a constant damping ratio for all wind power integration.

\section{2) Influence of Tie-Line Power Flow on the Small Signal Stability of a Power System.}

The SG2 was now taken out completely and then substituted with the same amount of wind power so that about $50 \%$ of the power produced in area one is from the wind farm. The system became unstable when exporting power to area two. However, when the direction of power flow in the tie-line was changed (i.e interchanging the load) so that power is imported from area two, the unstable modes at the right were pushed to the left side of the complex plane thus making the system stable. This is depicted in figures 6 and 7 (only the critical modes are shown on the complex plane for clarity.

Similar results were obtained when SG4 in area two was totally replaced by wind farm. The results also show a stable system for power import from area one to area two and unstable operation for power export from area 2 to area 1. 


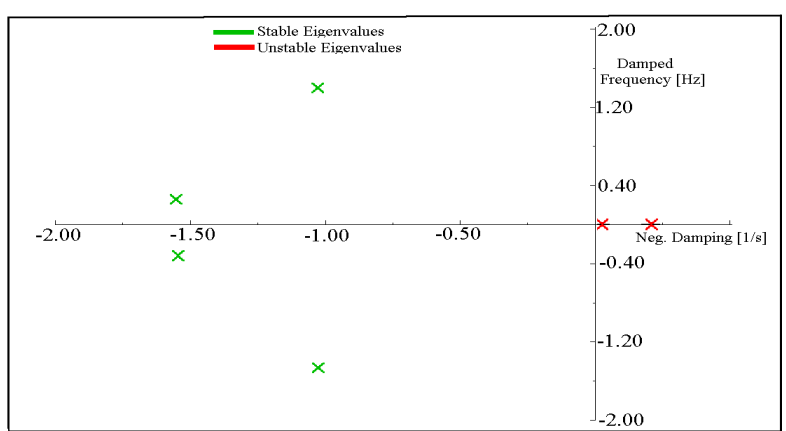

Figure 6: SG2 totally replaced by wind farm with power exported from area 1 to area 2

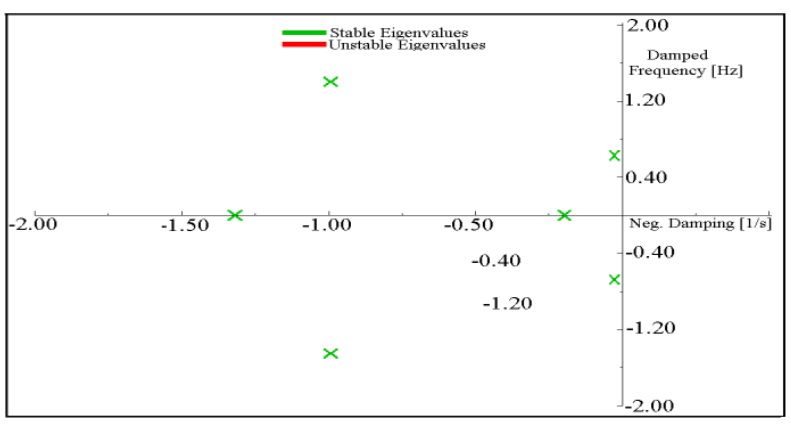

Figure 7: SG2 totally replaced by wind farm with power imported from area 2 to area 1

3) Impact of Transmission Line Length on the Small Signal Stability of a Power System

Most wind resources are found very far from the city where access to main grid is not available. The influence of the length of the transmission line to the main grid on the small signal stability is investigated. From the result in figure 8 , it seems the length of the transmission line does not have influence on both the local and the interarea mode.

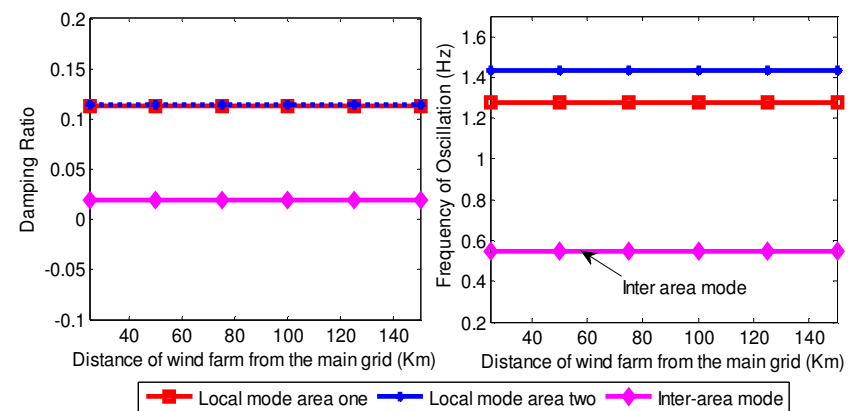

Figure 8: Influence of transmission length on the damping ratio and the frequency of electromechanical mode

\section{4) Change in Wind Generator Location}

The IEEE 9 bus test system was used to study the influence of change in wind generator locations on the small signal stability of a power system. Synchronous generators at bus 2 and bus 3 were taken out in turn and substituted with the same amount of wind farm.

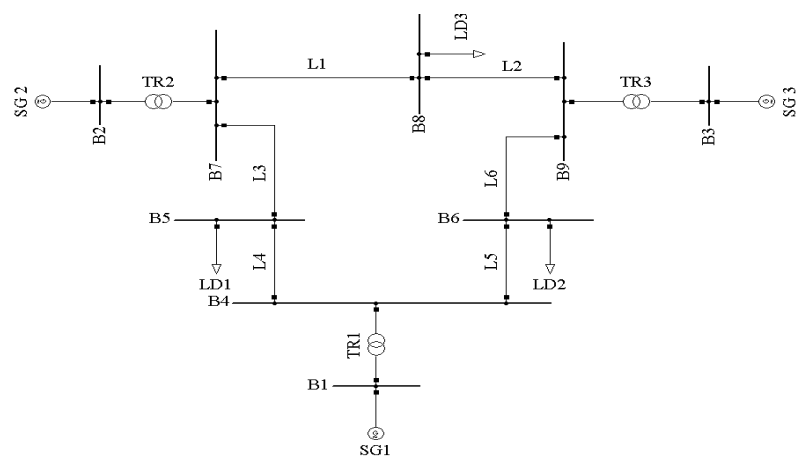

Figure 9: IEEE 9 bus benchmark

16 eigenvalues were computed first for SCIG technology. All the eigenvalues have negative real part for the three scenarios considered indicating that the system is small signal stable in all the cases. Electromechanical modes are picked out and presented in table 2 according to the rule relating to frequency of oscillation i.e

$0.2<f<2.5 \mathrm{~Hz}[12]$.

Table 2: electromechanical eigenvalues, frequency and damping ratio of IEEE 9 bus using SCIG technology

\begin{tabular}{|l|l|l|l|}
\hline SCIG & $\lambda=\sigma \pm \mathrm{j} \omega$ & $f, \mathrm{~Hz}$ & $\xi$ \\
\hline 3SG & $-0.785 \pm 10.990$ & 1.749 & 0.071 \\
\hline WF at B2 & $-1.239 \pm 15.073$ & 2.399 & 0.062 \\
\hline WF at B3 & $-0.867 \pm 8.292$ & 1.320 & 0.104 \\
\hline
\end{tabular}

From table 2 it can be inferred that wind farm (SCIG) can have both positive and negative influence on the damping of the oscillatory mode depending on the location. When WF is connected to bus 2, the damping ratio of the oscillatory mode decreases. The oscillatory modes are better damped when the wind farm is connected to bus 3, $(\xi>10 \%)$.

The wind farm technology was again changed to DFIG. The elecromechanical modes are presented in table 3 .

Table3: Electromechanical modes (DFIG)
\begin{tabular}{|l|l|l|l|}
\hline DFIG & $\lambda=\sigma \pm \mathrm{j} \omega$ & $f, \mathrm{~Hz}$ & $\xi$ \\
\hline 3SG & $-0.785 \pm 10.990$ & 1.749 & 0.071 \\
\hline WF at B2 & $-1.654 \pm 17.578$ & 2.398 & 0.094 \\
\hline WF at B3 & $-1.002 \pm 13.675$ & 2.177 & 0.074 \\
\hline
\end{tabular}

The wind farm (DFIG) has a better damping in all the locations considered. The participation factors of the electromechanical modes are presented in table 4 .

Table 4: Participation factor

\begin{tabular}{|c|c|c|c|c|}
\hline $\begin{array}{c}\text { DFI } \\
\text { G }\end{array}$ & $\lambda=\sigma \pm j \omega$ & variables & $\begin{array}{c}\text { Magni } \\
\text { tude }\end{array}$ & Angle \\
\hline $\begin{array}{c}\text { WF } \\
\text { at } \\
\text { B2 }\end{array}$ & $-1.654 \pm 17.578$ & SG1 speed & 0.953 & -170.63 \\
\cline { 3 - 5 } WF & SG3 speed & 0.051 & -165.72 \\
$\begin{array}{c}\text { at } \\
\text { B3 }\end{array}$ & $-1.002 \pm 13.675$ & SG2 speed & 0.921 & -173.6 \\
\cline { 3 - 5 } & & SG2 phi & 1 & 0 \\
\hline
\end{tabular}


The modal phasor diagram for DFIG wind farm at bus 3 is presented in figure 10

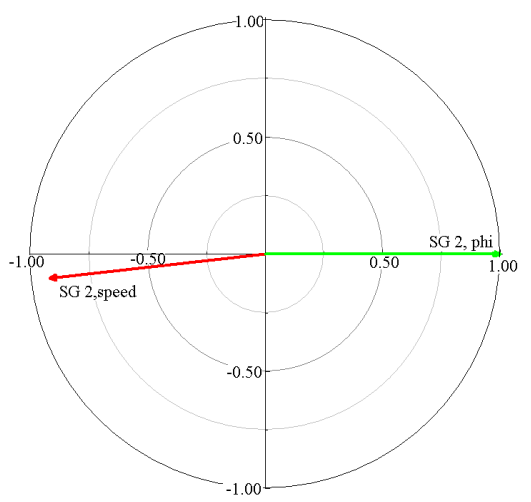

Figure 10: Phasor modal plot of the electromechanical mode when wind farm is connected to bus 3

From the participation factor computed, it can be seen that wind farm itself does not contribute to the electromechanical modes.

\section{Conclusion}

The influence of wind power on the small signal stability of a power system has been studied on four machine two area network and the IEEE 9 bus system as a benchmark. From the studies, wind power has positive influence on the damping of local area modes. DFIG has a better damping influence on the inter-area mode than the SCIG. The direction of wind power dispatch on the stressed tieline has influence on the small signal stability of a power system. In this study, the system is small signal unstable when about $50 \%$ of power produced in an area is exported over the weak tie-line. However, the system is stable for power import.

The length of the transmission grid from the wind location to the main grid seems not to have an influence on both the damping and frequency of oscillation of both the local area and the inter-area modes. The location of wind farm made of SCIG technology can have both positive and negative influence on the damping of the oscillatory mode depending on where the wind farm is located. However, with doubly-fed induction generator technology, the wind farm is seen to have better damping in all the locations.

In this paper, a qualitative study mainly is carried out on small test systems. Further investigation is necessary for large power systems.

\section{Acknowledgement}

The authors want to acknowledge the Tshwane University of Technology, National Research Foundation
(IRDP fund) and ESKOM (TESP) for the support of this research.

\section{References}

[10] J. Conroy and R. Watson, "Aggregate Modelling of Wind Farms Containing Full-Converter Wind Turbine Generators with Permanent Magnet Synchronous Machines: Transient Stability Studies," IET Renewable Power Generation, vol. 3, pp. 39-52, 2009.

[11] M. A. Poller, "Doubly-fed induction machine models for stability assessment of wind farms," in Power Tech Conference Proceedings, 2003 IEEE Bologna, 2003, p. 6 pp. Vol.3.

[12] W. Chen, S. Libao, W. Liming, and N. Yixin, "Small signal stability analysis considering grid-connected wind farms of DFIG type," in Power and Energy Society General Meeting - Conversion and Delivery of Electrical Energy in the 21st Century, 2008 IEEE, 2008, pp. 1-6. 